\title{
1 Intervention Research as Management Research in Practice: \\ 2 Learning from a Case in the Fashion Design Industry
}

3 Abstract

4 Research in the field of management and organizational sciences has yielded a deeper

5 understanding of many emerging business issues. However, the relevance of the contributions has been increasingly criticised, in both the academic and public spheres. This paper proposes the Intervention Research approach - originally developed by the research group at Ecole des Mines de Paris - as a design-science approach able to address both the relevance gap issue and the growing complexity of management practice. It is argued that increasing our understanding of management requires research that is more insightful, influential, and immediately applicable. This in turn requires closer collaboration between management and researchers during the inquiry process, which is not always easy to achieve. An illustrative case study of an intervention research project focusing on creativity, conducted in Italy in collaboration with a fashion company, demonstrates how intervention research can be rigorous and relevant to practitioners, and how it can advance theoretical knowledge in management science.

Keywords 


\section{Introduction}

Management research is being increasingly challenged for its limited impact on business and government (Fincham and Clark, 2009; Hodgkinson and Starkey, 2011). This criticism creates an opportunity to introduce novel perspectives on management research that more satisfactorily address the relevance dimension. Specifically, several authors have proposed moving beyond the traditional treatment of management research as an 'explanatory science' oriented to description, explanation and prediction of phenomena, and embracing instead a 'design science' perspective. This perspective seeks to assimilate the scientific quest for truth ('is this proposition true?') into a practical concern for relevance ('will it work better?') (Jelinek et al., 2008). Design science calls for the production of knowledge and artefacts that simultaneously advance our body of knowledge and improve performances (Van Aken, 2005).

The opportunity to adopt a 'design science' perspective has sparked considerable debate in the research community. However, actual approaches that engage in 'design science' are still infrequent, and have yet to gain high visibility and legitimacy in the research community (Symon et al., 2008). Intervention Research (IR) provides a salient example. IR seeks to design changes within organizations by enumerating the dynamics by which such changes are contextualized and formalized (Hatchuel, 2001). IR has by now reached theoretical maturity ${ }^{1}$ (David and Hatchuel, 2008) but only a limited number of published empirical research can be found in the literature. The reasons for this lack of exposure are twofold: First, existing contributions do not fully communicate the potential of IR in terms of advancing theoretical knowledge, practical relevance, and scientific rigor. Second, there is a lack of illustrative knowledge about the workings of IR since there is little English-based literature that maps out and clarifies the essence of its inquiry process.

\footnotetext{
${ }^{1}$ Two distinct IR approaches have been developed in two French Institutions, namely Ecole des Mines de Paris and ISEOR and Institue d'Administration des Enterprises, University Jean Moulin Lyon. The focus of this work is on the approach developed at Ecole des Mines de Paris.
} 
The aim of this paper is to advance the dissemination of IR by addressing these two issues.

In the first two sections of the paper we will identify six theoretical and practical challenges in management research that point towards the added value of a 'Design Science' perspective, and describe how these are theoretically fulfilled by IR. The final two sections present a case study that illustrates the implementation of IR inquiry process and how it concretely produced rigorous and relevant to research and practitioners.

\section{Research challenges in Management Research}

Emerging approaches to Management Research are likely to be legitimized by their capacity to support the production of knowledge which (a) advances the theoretical field; (b) is scientifically rigorous; and (c) is usable by practitioners (Cassell and Lee, 2011). In particular, new research approaches are likely to emerge if they help researchers address challenges that still inhibit their production of rigorous and relevant research.

What are these challenges? This question is open to multiple answers. Challenges depend on the "knowledge-constituting assumptions" (Johnson et al., 2006) that researchers adopt to substantiate the notions of "rigor" and "relevance". 'Design science', in this regard, moves from a non-positivist stance by which: (a) society does not manifest regularities, but rather continuous processes of change; and (b) reality is the result of social construction and cannot be neutrally accessed by external observers. Adopting this standpoint, researchers face the following major challenges.

\subsection{Theoretical Advancement of Management Science}

Theoretical advances depend on the ability to accommodate the inherent complexity - structural and dynamic - of both management and organizations. Three features are required.

Focus on change and development. Researchers are increasingly embracing a view which incorporates change into the core of their investigations in order to supersede the emphasis on a stable reality that characterizes positivism (Tsoukas and Chia, 2002). Escalating uncertainty and 
competition force organizations constantly to change in an effort to retain a sustainable advantage (Buchanan et al., 2005). Change is thus the key subject of research, because it is precisely the capability that organizations seek to cultivate and institutionalize (Van de Ven and Poole, 1995). Its investigation requires the emergence of approaches which can take systematic account of the dynamism of organizational actors and managerial decisions.

Support for multi-level analysis. There is growing recognition that organizations are affected by factors located at multiple levels of analysis and cannot be fully disentangled. Pfeffer (1997) recognized that attention should be paid to "(a) the effects of social organizations on the behaviour and attitudes of individuals within them; (b) the effects of individuals' characteristics and actions on organizations, with particular emphasis on the powerful individual influences that may exist within organizational systems; [...] (c) the mutual effects of environments--including resource, task, political, and cultural environments--upon organizations and vice versa" (p. 4). This complexity opens various venues for improvement, such as improving the micro-foundations of macro-macro relationships (Abell et al. 2008), building reliable meso-level constructs (Mathieu and Taylor, 2007), or introducing multi-level models able to control for 'unobserved heterogeneity' (Klein et al. 1994). The dominant approaches recognize these needs, but struggle to meet them (Payne et al., 2011). Emerging approaches suitable for investigating individuals, teams, firms, and environments within a single theoretical framework would thus be of primary interest.

Facilitate polyphonic investigation. The recognition of organizational complexity and dynamism entails a shift to a non-deterministic stance "whereas any human being is an agent capable of making choices based upon his or her inter-subjectively derived interpretation of the situation. Hence, social scientists, in order to explain human action, have to begin by understanding the ways in which people, through social interaction, actively constitute and reconstitute the culturally derived meanings which they deploy to interpret their experiences and organize social action" (Morgan 1980, p. 608). An understanding of reality as a social construct entails a demand 
for approaches able to tackle the polyphonic nature of management and organizational behaviours, so as to build a rational account of existing social interactions (Hoskisson et al., 2002).

\subsection{Rigor of Management Research}

Another crucial challenge is legitimizing the rigor of methodological commitments (Johnson et al., 2006), thereby ensuring that the knowledge yielded by emerging approaches is scientific. There are two main challenges in this regard.

Providing evaluation criteria. Proponents of new approaches are required to exhibit a 'new sensitivity' (Willmott, 1998), i.e. clarity in communicating the epistemological assumptions and the methodological implications of their research. There is no single best set of criteria on which all approaches should ultimately converge: different epistemological 'models of engagement' entail different evaluation criteria. Each set of evaluation criteria is legitimate if it is internally consistent with the epistemological assumptions, research goals, and methodological commitments of that particular mode of engagement (Johnson et al., 2006). Hence, assessing the rigor of an emerging approach is not a matter of proving its consistency with pre-established criteria, but rather clarifying its epistemological and methodological foundations and then defining "evaluation criteria" that are consistent with them.

Improving access to data. A basic pre-condition for rigor is the quality of the data supporting the theoretical framework. Collaboration with practitioners has been suggested as a crucial requirement for obtaining better data sets (Rynes, 2009). This may be a problem, given practitioners' lack of interest in academic research. This research-practice distance may severely limit the extent to which researchers are allowed to observe phenomena within organizations and interact with their members.

\subsection{Practical Relevance of Management Research}

Producing relevant knowledge is the greatest challenge faced by researchers. The divergence between researchers and practitioners has been widely studied, and evidence shows that few practitioners read scientific management journals (McKenzie et al. 2002) or explicitly use academic 
theories (Daft and Lewin, 1990). Some reasons for this lie on the practitioners' side, such as a lack of formal education or little exposure to research findings (Rynes, 2009), but the most prominent ones are imputable to the so-called 'relevance gap' of management research. This 'relevance gap' has been extensively debated in top-tier journals over the past ten years (Fincham and Clark, 2009). The debate has featured contrasting opinions about the potential trade-offs between managerial relevance and scientific rigor. Certain authors have claimed that this trade-off is unbridgeable (Kieser and Leiner, 2009), while others that reconciling relevance and rigor is not only possible and necessary but is already occurring (Hodgkinson and Rousseau, 2009). A major trend in management research is bridging this gap through active involvement of practitioners in the research process, and relying on multiple inquiry methods (Cassell and Johnson, 2006).

Collaborative Management Research (CMR) is the umbrella term that embraces various research approaches (e.g. action research, clinical inquiry, intervention research), each of which interprets 'participation' and 'inquiry' in its own way and has its own distinct epistemological and methodological foundation (Shani et al., 2008; Shani et al., 2012).

Henceforth, we will focus on a single CMR approach, Intervention Research, which seems able to meet the challenges set out above. We first provide a brief theoretical overview of the approach; this is followed by a review of the literature discussing the limited uptake of IR in the community, and its ability to address the challenges facing the management field.

\section{Intervention Research}

IR is an emergent collaborative process of inquiry that studies models of collective action within organizations. The works of Armand Hatchuel and Albert David provide an in-depth description of the epistemological assumptions and methodological commitments of IR (David and Hatchuel, 2001, 2008; Hatchuel, 1986, 2001, 2005, 2009; Hatchuel and David, 2008). We will outline such core concepts, then discuss IR limited diffusion, and finally manifest possible benefits from its wider adoption. 


\subsection{IR epistemological assumptions}

IR is marked by a departure from traditional theories of truth. Adopting the premises of Design Science, Hatchuel (2005) moves away from the traditional correspondence theory of truth and closer to Pierce' notion of workability, whereby “the only acceptable criteria [for truth] becomes that of the success of the experiment, a success which always relates to the initial aim of the subject" (p. 40). Pragmatism, however, "is not a theory of action but a theory of truth, defined as belief systems which can be revised through action. Action is reduced to the signs that cause beliefs to evolve" (ibidem). Pragmatism - along with postmodernism, dialogic relativism, and constructivism - is criticized for being grounded on a metaphysics of action, that reduces action "to a single principle or subject (individual or collective) without understanding how this principle or subject works" (ibidem). This is considered a crucial limitation because "management needs an epistemology that does not put action forward as a solution [to a problem of truth] but as the central, enigmatic question - the real subject of research and the grounds for its critique" (p. 41).

Accordingly, in IR “the central epistemological issue is not 'truth' but 'action'. This does not mean that academic management should turn to a pragmatic or practical epistemology where action is seen simply as the 'hands-on' solution ... 'Action', be it a phenomena to observe or the observing process itself, is the central theoretical enigma and not a ready-made and obvious universal" (p. 37).

\subsection{IR research purpose}

The epistemology of action is incorporated into IR, which seeks to identify, evaluate and formalize models of collective action (Hatchuel and David, 2008). Researchers study the theoretical assumptions that move specific actions (innovation, decision-making, democratization) and formalize this knowledge into models of collective action. Hatchuel et al. (2006) provides an example. The capability of two firms to continuously improve their products is here examined, leading to the identification of a common model of collective action - the design of product and knowledge lineages - that could be adopted by any other organization. The authors then elaborated 
that researchers can best meet their theoretical goal - identify models of collective actions - when they intervene in the organizations. Intervention is not a research outcome nor the provision of hands-on solutions. It is, instead, the process in which researchers can experience collective action "from the inside" and thus have more direct access to it.

The focus on the theoretical assumptions of action and their formalization into models mark the crucial differences between IR and its closest companion, Action Research (AR). IR stands in explicit continuity with AR, applying two of its features: (a) fostering changes in organizations while generating scientific knowledge; (b) practitioners' active participation into research. Building on these premise, IR sought to overcome the recurrent criticism that "it would be unusual for AR to deliver fundamental new theories" (Eden and Huxham, 1996) because AR “[does not] aim at contributing to management models valid outside the investigated context, which would be required to build a research program" (Hatchuel and David, 2008, p. 147). AR modifies the contextual theories-in-use of researched organizations. It represents itself one model of collective action, useful to innovate organizational practice, not a research program devoted to their investigation. IR, instead, "defines its purpose as the potential revision of established theories-inuse and improving CTUs is therefore interesting only if it leads to such a revision" (p. 148). Stated otherwise, AR could be a possible object of investigation for IR. AR and IR, in fact, move on two different theoretical levels. AR seeks to introduce contextual changes through a collaborative research protocol. Scientific knowledge is both produced and applied within the context of application. IR use the case(s) under investigation as a "pretext" to access the established theoriesin-use that characterize the organizational field - and organizations as a consequence. Scientific knowledge is here produced in a specific context of application, but transferred to the level of a general theory of action. The "transferability" of IR is not the generalization of findings, but rather the possibility to use its products - i.e. models of collective action - outside the boundaries of the original research context.

\subsection{IR methodological commitments}


IR incorporates any method that enables the contextualization of action and its formalization into models, tools, and procedures. No method is privileged because "rigor needs the combination and integration of a variety of research methods tailored to the model of action under study" (Hatchuel, 2009, p. 1459). Two minimum requirements regard the use of polyphony and practitioners' participation in research. Polyphony is inevitable for 'good' IR. The investigated phenomenon is by definition collective and researchers can understand it only by addressing the multiplicity of actors and interests involved in it. IR is thus regulated by a principle of isonomy, whereby the effort of understanding must be applied equally to all the actors involved. This principle occurs in a context of active participation of practitioners in the research process, whereby the research team must include those practitioners that represent the multiple views and interests of those called to interpret, adopt and innovate the collective action.

Polyphony and isonomy establish an "increased rationality" within the research team as IR must "[introduce] dialogue between the actors [and address] the compatibility of relations and new knowledge [between actors]" (David, 2002). Models of collective action are thus the result of a collective action in which all parties have to reach an agreement.

\subsection{Diffusion of IR in the literature}

Only few applications of IR have been published in the English language. ${ }^{2}$ Several reasons can be advanced to explain this shortcoming: (i) IR is time-consuming for researchers and long-committing for practitioners; aspects which restrict the possibility to apply the approach on a large scale; (ii) the 'knowledge gatekeepers' of mainstream journals are reluctant to accept IR-related work for publication; and (iii) researchers hesitate to use the approach because there is no body of knowledge that recognize and build upon the works of predecessors, and IR community of practice is limited to few academic groups.

\footnotetext{
2 The full list of references in English is: Borjesson and Elmquist (2011); Daniell et al. (2010); Magnani and Struffi (2009); Kling (2006); Rochet et al. (2009); Segrestin (2005, 2009); Stassart et al. (2011); Steyaert and Jiggins (2007); Steyaert et al. (2007).
} 
We argue that the primary concern is gaining visibility and convincing potential adopters rather than gatekeepers - of its validity. Two issues are overlooked: (a) why should I, researcher, adopt IR over other approaches? (b) How could I put IR into practice? Regarding the first point, Hatchuel and David's contributions already provide a sound understanding of the key concepts and epistemological shifts provided by IR. However, the theoretical debate on IR need a more researcher-based analysis of how concepts such as 'model of collective action', 'isonomy' and 'collaborative protocol' are valuable in addressing research challenges. Regarding the second point, Hatchuel and David (2008) provide a general description of IR research protocol. Published empirical works, however, do not clarify how Hatchuel and David's (2008) guidelines can be operationalized. On the contrary, there is methodological confusion in demarcating IR from other forms of collaborative research and in explaining the nature of IR contracts with partners.

Henceforth, we seek to address these gaps. First, we show IR contribution in addressing the challenges described in Section 2. Second, we provide an illustrative case of IR application intended to shed light on its research steps. Finally, we provide an account of models of collective action and their theoretical and practical relevance.

\subsection{IR responses to the six challenges in the management field}

A careful examination of IR suggests that its epistemological assumptions and methodological commitments have the potential to address the six challenges confronting the management field.

Focus on change and development. The introduction of IR has been occasioned by the inability of traditional approaches to provide an "understanding of how to develop innovation capabilities in organizations" (Hatchuel et al., 2008, p. 294). Organizations have very few principles to guide the identification of innovative processes (Hatchuel et al., 2008). IR works to fill this breach by grounding its investigation in collective action. By means of this epistemological shift, IR implements a design logic whereby "the aims of IR are precisely to study the theoretical assumptions of existing management models, to detect and validate innovative ones in pioneering organizations, or to design new ones whenever possible” (Hatchuel and David, 2008, p. 151). 
'collective action'. The concept of collective action entails a multi-level analysis of phenomena, because the behaviours of individuals, teams, and organizations need to be investigated through their mutual interactions. In fact, IR is grounded in the assumption that "the firm is not a collective that can be isolated naturally, and the permanent revising of its boundaries (physical, legal, human, commercial, etc) is a condition of its existence" (Hatchuel, 2001, p. S35).

Facilitate polyphonic investigations. The emphasis on polyphony with IR is twofold. On one hand, looking for collective action entails investigating how multiple actors operate at different levels in the organization - i.e. top and middle management, workforce - and requires the collection of information from multiple sources to understand the contribution of each actor. Polyphony thus becomes a methodological requisite for reliable results, because collecting data from a single source would introduce an obvious bias and gap in the analysis. On the other hand, polyphony is part of IR axiology. The principle of isonomy grants equal rights to all organizational members to discuss issues with researchers. IR treats the actors as equals in the research process, meaning that it is not biased toward specific interests. The expected outcome of IR is the creation of benefits shared within the organization: "the value of the entire project lies ... in the capacity to create fruitful, continuous cooperation while fully respecting the different identities of the partners" (Hatchuel and David, 2008, p. 154). At the same time, IR seeks to maintain the independence of research and the primacy of researchers over local pressures from both management and workforce. Isonomy in IR is not "democracy, nor even full participation in the knowledge produced. It is only the equal right to discuss the order of a collective process even if there is no equal right to rule it" (p. 153).

Provide clear evaluation criteria for rigor. An important point is the definition of criteria by which an external evaluator can appraise the rigor of IR research. As anticipated, the evaluation criteria need to be consistent with the epistemological assumptions and methodological commitments of modes of engagement (Johnson et al., 2006). In the case of IR, they are: (a) a realist ontological stance on reality, which is considered to have an independent existence prior to 
human cognition; (b) an inter-subjectivist stance on human behaviour, whereby individuals are seen as active enablers of change; (c) a subjectivist epistemology of truth, since the active involvement of practitioners in the research team rules out the possibility that researchers may merely passively record the facts of the phenomenon. Consequently, IR differs markedly from positivist research in its notion of 'epistemology of truth'. IR entails the inapplicability of the positivist criteria of internal, external and construct validity. Instead, the evaluation criteria for IR can be patterned on those described by Johnson et al. (2006) for Critical Theory. It is worth noticing that IR is not grounded on Critical Theory: "we must refuse the idea of relativism per se advocated by critical movements and post-modernist trends, which leads ironically ... to a blind reliance on metaphysics of action, that is, false universals of action (Hatchuel, 2005, p. 37). Neither does IR conceive its intervention in the Critical terms of emancipation from socio-historical dominations. These differences are strong enough to keep IR significantly distant from Critical Theory in terms of research objectives, perspectives and instruments. At the same time, IR and Critical Theory share aspects of their research that suggest a comparable use of evaluation criteria. On one hand, they both employ a subjectivist epistemology that opposes positivist neutrality and dismisses generalisability as an inapplicable criterion in favour of 'accommodation' - i.e. the use of knowledge in diverse, comparable contexts where similarities and differences can be assessed. Second, they both put change at the core of their research aims. They give two significantly different meanings to change, but their research can be similarly appraised in terms of 'catalytic validity, i.e. the extent to which the research elicits a new understanding of reality in the people involved (Kincheloe and McLaren, 1994). Third, it is crucial in both approaches that the knowledge produced is credible to those who have participated in its development (Kincheloe and McLaren, 1994). This credibility is expressed in terms of 'authenticity', i.e. the extent to which research findings represent agreement on what is considered to be true.

Facilitate access to data. The long-term collaboration established by the IR contract and the relevance of its 'design' artefacts for organizations generate a closer commitment of 
organizations to the research endeavour. Practitioners' interest in the research results may reduce the distances between researchers and the phenomena observed. Researchers are, in fact, allowed to conduct more extensive and deeper observations of behaviours and contexts which accrue to the scientific validity of findings. Moreover, the participation of practitioners and the principle of isonomy granted to any organizational member are two opportunities for the collection of more genuine accounts of behaviours and contexts. The inclusion of practitioners in the research team is consistent with an anti-positivist stance which rejects the possibility of truly external observations. At the same time, IR researchers communicate the nature of their contractual agreement, so as to enable peer reviewers' evaluation of its rigor and appropriateness.

Provide relevant knowledge to practitioners. IR does not provide practitioners with 'handson solutions' to specific problems. The theoretical output of the intervention process - the understanding or development of 'models of collective action' - is indeed the relevant output for practitioners. This approach resonates with Lewin's (1951) observation that "there is nothing so practical as good theory"'(p. 169). At the core of this intuition is the assumption that research must foster managerial awareness of the models, tools, and procedures which can improve the capacity to enact actual changes. Table 1 below summarizes the theoretical discussion, detailing how IR addresses the identified challenges.

\section{Insert Table 1}

\section{Illustrative case}

In this section we illustrate IR inquiry process and the formulation of 'models of action'. The case involved one of the top-five producers of silk for big-name fashion customers, located in Northern Italy. The research begun in January 2009 and is still in progress. Table 2 provides an overview of the case. 


\subsection{Topic under study}

The study aimed at investigating the design of creative processes within organizations. Unlike typical AR designs, the research did not intend to address a contextual problem - e.g. improve the creative processes of an organization - but to understand, formalize and innovate the established theories-in-use for creativity. The "intervention" involved the production of (theoretical) models of creative action that could ground new processes, tools and capabilities.

The research originated from a gap in the literature of 'team creativity', i.e. its study in 'isolation' from organizational processes and individual behaviours despite the fact that multi-level influences (individual characteristics, intra-team and extra-team interactions, work environments etc.) simultaneously determine the nature and outcomes of team creativity (Kylen and Shani, 2002). This suggested the opportunity to adopt a collective creativity perspective which studied team processes as they emerge from individuals and from organizational processes. Collective creativity refers to the creative ideas developed within the work context as outcomes of exchanges in a collective space, when individual interactions trigger ideas through dialogue and debate (Chen, 2006). Creativity at the collective level has received relatively little attention (Kurtzberg and Amabile, 2001), and key gaps in our knowledge include a need for (1) integration between the different levels of analysis; (2) reconciling the objectives and interests of different actors, both internal and external, and (3) coherent and holistic models of action that support practitioners adapting to organizational dynamism. These gaps suggested the use of IR, under the umbrella of the CMR orientation, in order to generate an understanding of models of collective creativity in organizations.

\subsection{Company selection and engagement}

Case selection was purposive. The researchers searched an organization that (a) could manifest the established theories-in-use in its creative processes and (b) strived for improvement. The nature and ongoing challenges of creativity in the fashion and design industry made the choice of industry 
relatively simple. We approached a company that was among the top-five designers of premium silk products for high-end fashion labels. The company targeted a market niche in which creativity is fundamental since clients include some of the biggest players in the fashion industry. Initial meetings with the top management indicated that creativity was an area of major concern, and the firm was willing to have a long-term commitment to research. The research proposal thus met the excitement of a CEO which saw the possibility to attain potential breakthroughs, build new organizational capabilities.

\subsection{Methodological Overview}

IR does not impose any methods, but requires involving any relevant actor that is knowledgeable about or involved in creativity, maintaining isonomy, whereby all actors are granted equal access to research, and being consistent with the epistemology of IR. The study progressed accordingly. First, we identified a research team involving three distinct actors in the organization - i.e. product manager, human resource manager, designer. The combined expertise of these actors covered the entire creative process and represented the specific interests that needed to be accommodated. The need for a continuous involvement in the research process limited the number of employees that could be allocated in the team. Other employees were involved differently. CEO, product manager, salesperson, designer, brand manager, colour expert and print technician were interviewed and sought for feedbacks during the study. Their inclusion covered the multiple voices that informed the research of the local interests, opinions and constraints that were present in creative processes.

The research team established roundtables - both metaphorically and literally - as the ideal condition in which everyone in the research team could freely contribute to the investigation. This was sufficient to create isonomy, because it prevented "hidden profile" behaviours (Thomas-Hunt et al., 2003) and established "psychological safety" (Edmondson, 1999) within the team. Data were collected with multiple techniques. In general terms, the research combined different qualitative (interviews, observations) and quantitative techniques (an exploratory survey) which were all instrumental to a common purpose, i.e. understand the social interactions, contextual conditions and 
individual involvement that characterize creativity processes. These data were processed by the research team during the roundtable meetings in order to develop models of collective actions.

\subsection{Inquiry process}

The research has evolved in an ongoing set of collaborative investigations. The inquiry process is described using three macro-phases proposed by Avenier and Nourry (1999). The following paragraphs provide a summary of two sequential studies. The first study aimed at exploring the definition of creativity and its key elements in order to develop a model of action that could help the company improve its financial performance. The second study aimed at identifying a model of action for designing and managing the organizational variables to sustain creativity.

\section{First study}

Collaborative research process design. The research team - consisting of three academics and three practitioners - defined a timeline that was announced to the organization. The research team explored different alternative research methods and chose in-depth semi-structured interviews. The team crafted the interview questions drawn from various sources in the scientific literature and developed the interview protocol. The team identified the organizational members (described in the previous paragraph) to be interviewed, and decided that its academic members would conduct the interviews. The team held regular meetings to discuss the findings, upcoming steps in the research process and to consolidate results into a shared solution.

Understanding the phenomenon under inquiry. Interviews were conducted with the members of the top management team, and key product managers, designers, colour experts and salesmen (all the different roles existing in the unit). The interviewees were selected by the research team on the basis of their knowledge and role in the three most representative projects - each representing specific client groups. The interviewees were first contacted by a corporate member of the team; they were then sent an e-mail describing the objectives of the research project, the methodology, and the structure of the interview. All the interviews were conducted face-to-face, lasting 45-90 
minutes. Each interview was conducted by two researchers randomly assigned to conduct the interview. A total of twenty-one interviews were conducted and all were taped and transcribed. Data were analyzed on a set of default variables: meaning of creativity, key influential factors, characteristics of the process, needed competencies, and achieved outcomes. Each transcribed interview was read, coded and analyzed by two different researchers, through a series of team meetings, re-readings and re-codings where the properties of emergent macro-variables were reconfigured and focused. A comprehensive analytical report was prepared. In addition to data triangulation (collecting data from a variety of sources), an investigator triangulation was implemented (more than one researcher analyzing data). At the completion of the analysis, in order to assure interpretation validity, external readers with knowledge and experience in the topic also reviewed the data. The data were organized on the basis of the macro-variables, preserving the anonymity of the interviewees. The document, including both paradigmatic raw responses and the content analysis, was shared with the research team for collective validation, sense-making and meaning creation.

Implementation process. The research team arrived at a shared interpretation of data.

Definitions and key issues arising from the data were discussed. The research team also shared the data document and its interpretation with top management. Top management was invited to participate in data interpretation with the research team. Thereafter, organizational members were invited to take part in the process. The result was a session in which 31 people, representing all the different points of view at each level, attended a three-hour workshop devoted to sense-making and devising actions to address some of the issues identified in regard to collective creativity. In this way, a wide variety of stakeholders participated in making decisions on collective creativity to achieve improvements and effective results. The last part of the meeting was devoted to present suggested action items to top management, which in turn made a public commitment for both action implementation and actions for further study. 
Outcomes of the effort. The resulting model confirmed that creativity occurs at a collective level within the organization. The notions of team/group creativity had to be extended: "collective" refers to a group of a limited number of people, working at various levels of reciprocal dependence, with a common final purpose. The emerging model of action flows into the concept of "collective creativity", discussed by few scholars in past research (Hargadon and Bechky, 2006). Collective creativity can be defined as a purposeful set of processes, activities and mechanisms established by individuals within an organization, which are a part of a larger social and professional network, through which a novel idea, product, service, or procedure is generated. The study advanced the theoretical understanding of this phenomenon through a set of propositions regarding the concept of collective creativity and a dynamic design-based framework for collective creativity development. It is multi-level, including contextual factors, organizational factors, collective creativity factors (such as which includes people, skills and knowledge; processes and routines; structures), and collective creativity output. The model of action had implications for both academia and practice. The scientific knowledge generated included a master's thesis and papers presented at academic conferences. The company also used the insights to guide and implement changes in the organization. For example, the original functional organization of the Design unit, with a distinction among designers, technicians, colour experts, etcetera, was altered by instituting the role of vicepresident of product/collection development and creating four divisions in which members with different roles could synergistically develop creative solutions for each product cluster.

\section{Second study}

\section{Collaborative research process design. Given the results of the first study, the CEO} agreed to continue the collaboration. It was agreed that the follow-up study would use the same processes and mechanisms. The team met and refined the scope of the new study: identify the key organizational variables affecting the development of collective creativity, and examine how these can be enhanced through specific organizational learning mechanisms (Mitki et al, 2008). The research team discussed possible methodologies and decided to develop and administer a 
comprehensive survey with the aim of detecting evidence of association between organizational variables for collective creativity, and organizational learning mechanisms (Forza, 2002). In particular, a closed-question format was chosen to obtain a quantitative tool able to capture the above-mentioned associations. A survey instrument was built using both items from the literature (Garvin et al., 2008) and items created on the basis of the results from the first study. Most of the survey questions used a Likert scale (6-point). The survey instrument was validated by a combination of a careful review during few successive research team meetings and by a pre-test with a few organizational members. As a result some items were reworded and some were deleted from the survey.

Understanding the phenomenon under inquiry. The questionnaire was sent by email with a covering note from the CEO to each member of the "Product Design and Development" Unit. Two academic members of the research team were at employees' disposal for one full day, to address questions and doubts and to collect the questionnaires. 79 out of 99 people completed the survey at this stage. After an email reminder a total of 80 people completed the survey, corresponding to a response rate of $80.81 \%$. The collected data were statistically processed by the academic members of the research team. Different constructs were considered following previous research and confirmed by factor analysis. Means, standard deviations and correlations among variables were calculated. Linear regressions were used to analyze the data, in order to possibly support different hypnotized causeeffect relationships. The academic members produced a document that included the main results of the statistical analysis, assuring anonymity and readability by practitioners.

Implementation process. The document was shared with the research team for meaningcreation about the relationships emerging among the variables. A specific report on the study results was made available to everyone within the organization. Shared data interpretation continued in meetings among the research team, the CEO, and his management team. Possible managerial actions and next research steps were explored. 
Outcomes of the effort. The resulting model of action indicates that collective creativity, as defined above, is enabled and accelerated to the extent that the organization builds a tapestry of learning mechanisms (Shani and Docherty, 2003). This tapestry includes elements of each of the three kinds of learning mechanism - structural, procedural, and cognitive - makes it possible to accommodate and stimulate the requisites for collective creativity. The study attempted to support a set of stated hypotheses, highlighting the specific kinds of learning mechanisms that can enhance collective creativity and the relative outcomes. This model of action has implications for both knowledge production (doctoral and master's thesis, academic papers) and managerial insights (among others, a protocol for more accurate definition of roles was implemented, and an investigation into alternative designed and implementations of post-project review practices and their impact on collective creativity was launched).

\section{Discussion}

The case captures the implementation of IR, under the umbrella of CMR orientation, in a dynamic company within a competitive industry. Several issues could be addressed in the discussion. Owing to space limitations, though, this section will focus on the IR inquiry process and its implications for theoretical advancement, rigor, and relevance.

\subsection{Illustration of IR inquiry process.}

Past research does not offer detailed descriptions of the IR protocol that could enlighten researchers on how actually to design and lead the IR process. To fill this gap, this manuscript describes one example of IR-based that captured how IR process works and how it leads to models of collective action. The research was described by highlighting key activities in the three macro-phases: collaborative research process design, inquiry process and, implementation. Those activities are summarized in Table 3.

\section{Insert Table 3}

\subsection{IR and challenges of Management Research}


504 The challenges set out in Section 2 were all captured in the case (see Table 4), briefly reviewed and 505 discussed below.

Improving the study of organizational change and development. IR places the problem of change at the centre of a theoretical inquiry and seeks to support practitioners and researchers in designing the change. IR does so by combining the concern for contextualized knowledge typical of Action Research with an effort to formalize results into models of collective action. Stated otherwise, IR does not focus on solving specific creative problems or educating specific groups. IR used, instead, the experience of a pioneering organization to develop models of collective creativity. Specifically, 
of connections between the parties in order to achieve the 'best solution' possible about creativity. Polyphony is thus a methodological requirement and an expected result of models of action. In our case, this was achieved by delivering a model of collective creativity that connected top and middle management, designers, and blue collar workers. The parties were involved with a specific logic. They were first involved separately in order to appraise the multiple voices in the organization and recognize the existing tensions, and then joined the research team in order to design a model of collective action that could support not "any development" but one from which all parties could to some extent benefit. The connections were in part achieved by design - through regular roundtables - and in part as a result of in-progress decisions.

With respect to rigor, we identified two specific challenges. The first was devising evaluation criteria that enable external assessment of an approach's rigor. More specifically, for the IR approach, three criteria were proposed with which to evaluate the rigor of studies. The first of them is 'accommodation'. Considering the illustrative case, models of action were identified in order to enabled the company to reframe its managerial practices concretely, and to explore a wide set of possible managerial actions. This suggests that the models of action produced do not map out a rigid course of action, but rather generate guidelines that companies can adapt to specific situations, and which can thus be considered new organizational capabilities. The second criterion for assessing rigor is 'catalytic validity', which denotes the extent to which the research imbues the people involved in it with novel ways of understanding reality and of using that knowledge for positive change. At least three factors confirm that the case fulfilled the catalytic validity criterion: The response of organizational members at different levels (in terms of availability and openness in the interviews, response rate to the survey, attendance at the various meetings); the planned set of managerial actions arising from the findings, which the organization's managers actually implemented or committed to implementing in the long-medium term, and; the fact that the research project is still ongoing, demonstrating that the company regarded the collaboration as beneficial and so decided to continue working within the IR approach. Lastly, the third criterion by which 
Intervention Research rigor should be assessed is its 'authenticity'. The case fulfilled this criterion: the involvement of different organizational levels and units reflected an effort to incorporate the diverse representations of the phenomenon, and the many occasions devised to foster production of shared meaning confirm the commitment to ensuring that the knowledge produced was credible to all who took part in its development. The second challenge relating to rigor is to develop methods and approaches that systematically make access to organizational information more effective. In the case, there was a carefully designed collaborative protocol which included practitioners in the research teams. These joint teams explored different alternatives for the design and methods of the research, drafted the specific interview/survey questions and protocol, identified the organizational members to be interviewed, created commitment to the survey, and made sense of and created meaning from the results. The activities of the research teams were backed up by contractual agreements explicitly stating the research objectives, signed by the senior researcher and the CEO of the company for each study.

The final challenge is the ability to produce relevant knowledge for practitioners, which is the sixth challenge identified previously. It may appear evident from the discussion of earlier points that theoretical advances and practical relevance are tightly linked, because the latter is achieved through the former. The case fulfilled this challenge, since the resultant models of collective action supported the design and implementation of managerial models, tools, and procedures that facilitated organizational change. IR is intended to produce "hands-on" solutions - which may be valuable for a while but then leave organizations in need for further consultancy - but it instead acts at the level of capabilities, supporting organizations in the understanding and deployment of established theories-in-use. In fact, the company's top management implemented a number of decisions (restructuring of the organization, reviews of practices, redefinition of roles) based on the results of the studies, and also planned a further set of managerial actions to be implemented in the future. 
The discussion proposed above allows advancement of the idea that IR, viewed as one of the approaches included in the broader design science, seems to meet the challenges identified. At the same time, the case also highlights some limitations of this approach that require further investigation. First, IR requires significant resources both from academia and companies. From the academic point of view, the collaborative nature of the inquiry process requires experienced researchers, with comprehensive understanding of a wide variety of scientific methods and the ability to manage complex political dynamics. From the company point of view, the process can be only based on credible and reliable research teams with members able to focus effectively on management issues that are crucial for the company. In addition, the diverse knowledge base possessed by the research team implies that significant effort and resources will be needed to generate consensus among the members. In the case analyzed, the research teams consisted of skilled and experienced individuals that met on a regular basis for two years. This entailed a significant resource investment by both the company and the university.

The second limitation concerns the complexity of the organizational context in which IR takes place. Indeed, according to the key features of IR, managerial maturity and willingness to be involved in a complex collaborative process that not always be planned in advance, tends to raise both anxiety and uncertainty. This requires risk-taking management orientation directed more to the revision of the established theories-in-use in the organization than to authority and control. In the case, personal orientation of both the $\mathrm{CEO}$ and some members of the managerial team, coupled with a strong cultural tradition of a centenarian company, made the inquiry into critical issues possible, the result of which could not be predicted in advance.

\section{Conclusions}

This manuscript's contribution had its starting point on a diffused criticism of the (non-) relevance of management research and the opportunity to propel an approach that is consistent with a Design 
Science perspective. The focus of this study was on IR, and approach whose "intervention" seeks to individuate and improve the theoretical assumptions used by organizations ground their collective actions - innovation, decision-making, coordination. The manuscripts addressed in particular one problem, the seeming lack of diffusion of IR within the scholarly community. Two sub problems were singled out - the non-clarity of how this approach advances research (and helps researchers) and the limited understanding of the IR process.

The paper addresses both concerns, in order to stimulate the debate on, and hopefully the diffusion of, IR. First, the study demonstrated how IR can address multiple challenges in management research. IR can be appreciated as a double-edged sword in researchers' hands, as it can improve the understanding of how collective action works (and is interpreted) in an organizational setting and, at the same time, incorporates this knowledge into models, tools for organizations' consumption. Second, the manuscript reported a research experience to convey key decisions involved in the inquiry process of IR. The complexity of designing and managing IR might provide some insight into its limited diffusion. Yet, as this study illustrated, the simultaneous benefits generated for both theoretical development and managerial practice points towards the opportunity and the need to pursue further the potential embedded in this collaborative research orientation.

\section{References}

Abell, P., T. Felin and N. Foss (2008). 'Building Micro-foundations for the Routines, Capabilities, and Performance Links', Managerial and Decision Economics, 29, pp. 489-502.

Amabile, T.M. (1983). The social psychology of creativity. New York: Springer-Verlag New York Incorporated.

Avenier, M.-J., L. Nourry (1999). 'Sciences of the Artificial and Knowledge Production: The Crucial Role of Intervention Research in Management Sciences’, Design Issues, 15, pp. 55-70.

Borjesson, S. and M. Elmquist (2011), 'Developing Innovation Capabilities: a Longitudinal Study of a Project at Volvo Cars', Creativity and Innovation Management, 20, pp. 171-184. 
Buchanan, D., L. Fitzgerald, D. Ketley, R. Gollop, J.L. Jones, S.S. Lamont, A. Neath and E. Whitby (2005). 'No Going Back: a review of the literature of sustaining organizational change', International Journal of Management Reviews, 7, pp. 189-205.

Buono, A. and H. Savall (2007). Socio-Economic Intervention in Organizations: The intervener-researcher and the SEAM approach to organizational analysis. Charlotte, North Carolina, USA: Information Age Publishing, Inc.

Burrell, G. and G. Morgan (1979). Sociological paradigms and organizational analysis. Portsmouth, NH: Heinemann.

Cassell, C. and B. Lee (2011). Challenges and Controversies in Management Research. London, UK: Taylor $\&$ Francis.

Cassell, C. and P. Johnson (2006). 'Action research: Explaining the diversity', Human Relations, 59, pp. 783-814.

Chen M. (2006). Understanding the Benefits and Detriments of Conflict on Team Creativity Process. Creativity and Innovation Management Journal, Vol. 15, No. 1, pp. 105-116

Collier, J. (1945). 'United States Indian administration as a laboratory of ethnic relations', Social Research, 12, pp. 275-286.

Cook, T.D. and D.T. Campbell (1979). Quasi-experimentation: Design and Analysis for Field Settings. Chicago: Rand Mcnally.

Daft, R. and A. Lewin (1990). 'Can Organization Studies Begin To Break Out of The Normal Science Straitjacket? An Editorial Essay’, Organization Science, 1, pp. 1-9.

Daniell, K.A., I. White, N. Ferrand, I.S. Ribarova et al. (2011). 'Co-engineering Participatory Water Management Processes: Theory and Insights from Australian and Bulgarian Interventions', Ecology and Society, pp. 11.

David, A. and A. Hatchuel (2008). 'From actionable knowledge to universal theory in management research'. In A.B. Shani, S.A. Mohrman, W.A. Pasmore, B. Stymne, N. Adler (eds), Handbook of Collaborative Management Research, Los Angeles: Sage, pp. 33-47.

David, A., A. Hatchuel and R. Laufer, R. (eds) (2001). Les nouvelles fondations des sciences de gestion [The new foundations of management science]. Paris: Vuibert Fnege.

Deetz, S. (1996). 'Describing Differences in Approaches to Organization Science: Rethinking Burrell and Morgan and Their Legacy', Organization Science, 7, pp. 191-207.

Denyer, D., D. Tranfield, and J. E. van Aken (2008). 'Developing design propositions through research synthesis'. Organization Studies 29, pp. 249-269.

Donaldson, L. (1985). In defense of organization theory: a reply to the critics. Cambridge University Press.

Edmondson, A.C. (1999). 'Psychological safety and learning behaviour in work teams'. Administrative Science Quarterly 44, pp. 350-83.

Felin, T. and N.J. Foss (2005). 'Strategic organization: A field in search of micro-foundations', Strategic Organization, 3, pp. 441-455.

Feyerabend, P. (1979). Against method. London: New Left Books. 
671 Fincham, R. and T. Clark (2009). 'Introduction: can we bridge the rigour-relevance gap?', Journal of 672 Management Studies, 46, pp. 510-515.

673 Ford, J.D., L.W. Ford and A. D'Amelio (2008). 'Resistance to Change: the rest of the story', Academy of 674 Management Review, 33, pp. 362-377.

675 Forza, C. (2002). Survey research in operations management: a process-based perspective. International 676 Journal of Operations \& Production Management, Vol. 22, No. 2, 2002, pp. 152-194.

677 Freud, S. (1908). Creative writers and day-dreaming. Standard Edition 9, pp. 143-154

678 Garvin, D.A., Edmondson, A.C. and Gino, F. (2008) Is yours a learning organization?. Harvard Business 679 Review, 86, 3, 109-16.

680 Grey, C. (2001). 'Re-imagining Relevance: a response to Starkey and Madan', British Journal of 681 Management, 12, S27-S32.

682 Guilford, J. P. (1950). 'Creativity', American Psychologist, 5, pp. 444-454.

683 Hargadon, A.B. and B.A. Bechky (2006). 'When Collections of Creatives Become Creative Collectives: A Field Study of Problem Solving at Work', Organization Science, 17, pp. 484-500.

Hatchuel, A. (2001). ‘The Two Pillars of New Management Research', British Journal of Management, 12, pp. 33-39.

Hatchuel, A. (2005). Towards an epistemology of collective action: management research as a responsive and actionable discipline, European Management Review, 2, pp. 36-47

Hatchuel, A. and A. David (2008). 'Collaborating for Management Research, From Action Research to Intervention Research in Management'. In A.B. Shani, S.A. Mohrman, W.A. Pasmore, B. Stymne and N. Adler, Handbook of Collaborative Management Research, pp. 143-162. SAGE.

Hatchuel, A. and B. Weil (2009). 'C-K design theory: An advanced formulation', Research in Engineering Design, 19, pp. 181-192.

Hatchuel, A. and H. Molet (1986). 'Rational modelling in understanding and aiding human decision making', European journal of operations research, 24, pp. 178-186.

Hatchuel, A., P. LeMasson and B. Weil (2002). 'From knowledge management to design-oriented organisations', International Social Science Journal, 171, pp. 25-37.

Hatchuel, A., P. Lemasson and B. Weil (2008). 'Building Innovation Capabilities: the development of design-oriented organizations'. In J. Hage and M. Meeus (eds), Innovation, Science, and Institutional Change, Oxford: Oxford Press, pp. 294-312.

Hodgkinson, G.P. and K. Starkey (2011). 'Not Simply Returning to the Same Answer Over and Over Again: Reframing Relevance', British Journal of Management, 22, pp. 355-369.

Hoskisson, R.E., M.A. Hitt, R.A. Johnson and W. Grossman (2002). 'Conflicting voices: the effects of institutional ownership heterogeneity and internal governance of corporate innovation strategies', Academy of Management Journal, 45, pp. 697-716.

Jelinek, M., G.L. Romme and R.J. Boland (2008). 'Introduction to the Special Issue Organization Studies as a Science for Design: Creating Collaborative Artifacts and Research', Organization Studies 29, pp. 317-329.

Johnson, P., A. Buehring, C. Cassell and G. Symon (2006). 'Evaluating qualitative management research: Towards a contingent criteriology’, International Journal of Management Reviews, 8, pp. 131-156 
Johnson, P., A. Buehring, C. Cassell and G. Symon (2007). 'Defining qualitative management research: an empirical investigation', Qualitative Research in Organizations and Management: An International Journal, 2, pp. 23-42.

Kieser, A. and L. Leiner (2009). 'Why the rigour-relevance gap in management research is unbridgeable', Journal of Management Studies, 46, pp. 516-533.

Kincheloe, J.L. and P.L. McLaren (1994). 'Rethinking critical theory and qualitative research'. In N. Denzin and Y. Lincoln (eds), Handbook of Qualitative Research. London: Sage.

Klein, K. J., F. Dansereau and R.J. Hall (1994). 'Levels issues in theory development, data collection, and analysis', Academy of Management Review, 19, pp. 195-229.

Klein, K.J and S.W.J. Kozlowski (2000). 'From Micro to Meso: Critical Steps in Conceptualizing and Conducting Multilevel Research’, Organizational Research Methods, 3, pp. 211-236.

Kling, R. (2006). 'In Search of Efficiency - concurrent concept elaboration and improvement', Technovation, 26, pp. 753-760.

Kuhn, T. (1962). The Structure of Scientific Revolutions, Chicago: Chicago University Press

Kurtzberg, T. R. and T.M. Amabile (2001). 'From Guilford to creative synergy: Opening the black box of team-level creativity', Creativity Research Journal, 13, pp. 285-294.

Kylen S.F. \& Shani A.B. (Rami) (2002). Triggering Creativity in Teams: An Exploratory Investigation, Creativity and Innovation Management Journal, Vol. 11, No. 1, pp. 17-30

Lewin, K. (1946). 'Action research and minority problems', Journal of Social Issues, 2, pp. 34-46.

Lewin, K. (1951). 'Problems of research in social psychology'. In D. Cartwright (ed), Field Theory in Social Science. London: Social Science Paperbacks.

Lewis, M.W. and A.J. Grimes (1999). 'Metatriangulation: building theory from multiple paradigms', The Academy of Management Review, 24, pp. 672-690.

Lyotard, J.-F. (1984). The Postmodern Condition: A Report on Knowledge. Manchester: Manchester University Press.

Magnani, N. and L. Struffi (2009). 'Translation sociology and social capital in rural development initiatives. A case study from the Italian Alps’, Journal of Rural Studies, 25, pp. 231-238.

Mathieu, J.E. and S.R. Taylor (2006). 'A framework for testing meso-mediational relationships in Organizational Behavior', Journal of Organizational Behavior, 28, pp. 141-172.

McKenzie, C.J., S. Wright, D.F. Ball and P.J. Baron (2002). 'Commentary: The publications of marketing faculty - who are we really talking to?', European Journal of Marketing, 36, pp. 1196-1208.

Merton, R.K. (1968). Social Theory and Social Structure. Free Press.

Mitki, Y., A.B. Shani and T. Stjernberg (2008). 'Leadership, development and learning mechanisms. System transformation as a balancing act', Leadership \& Organization Development Journal, 29, pp. 68-84.

Mone, M.A. and W. McKinley (1993). 'The uniqueness value and its consequences for organization studies', Journal of Management Inquiry, 2, pp. 284-296.

Morgan G. (1990). 'Paradigm diversity in organizational research'. In J. Hassard and D. Pym (eds), The theory and philosophy of organizations: critical issues and new perspectives. London: Routledge. 
Newell, A. and H.A. Simon (1972). Human problem solving. Englewood Cliffs, NJ: Prentice Hall.

O'Dell, C. and C.J. Grayson (1998). 'If only we knew what we know: Identification and transfer of internal best practices', California Management Reviews, 40, pp. 154-174.

Pasmore, W., B. Stymne, A.B. Shani, S.A. Mohrman and N. Adler (2008). 'The Promise of Collaborative Management Research'. In A.B. Shani, S.A. Mohrman, W.A. Pasmore, B. Stymne and N. Adler (eds), Handbook of Collaborative Management Research, pp. 7-31. Thousand Oaks, CA: SAGE.

Payne, T.G., C.B. Moore, S.E. Griffis and C.W. Autry (2011). 'Multilevel Challenges and Opportunities in Social Capital Research', Journal of Management, 37, pp. 491-520.

Pettigrew, A.M., R.W. Woodman and K.S. Cameron (2001). 'Studying organizational change and development: Challenges for future research', Academy of Management Journal, 44, pp. 607-713.

Pfeffer, J. (1993). 'Barriers to the advancement of organization science: paradigm development as a dependent variable', Academy of Management Review, 18, pp. 599-620.

Pfeffer, J. (1997). New Directions for Organization Theory: Problems and Prospects. Oxford: Oxford University Press.

Repenning, N.P. (2002). 'A Simulation-Based Approach to Understanding the Dynamics of Innovation Implementation', Organization Science, 13, pp. 109-127

Rhodes, C. (2001). Writing Organization, (Re)presentation and Control in Narratives at Work. Amsterdam: John Benjamins

Rochet, C., J. Habib and E. Soldo (2009). 'The use of an information system as a legitimate subversive agent', Information Polity, 14, pp. 155-171.

Rynes, S.L., D.B. McNatt and R.D. Bretz (1999). 'Academic Research Inside Organizations: inputs, processes, and outcomes’, Personnel Psychology, 52, pp. 869-898.

Savall, H. and V. Zarbet (2011). The Qualimetric Approach: Observing the Complex Object. Charlotte, NC: Information Age Publishing, Inc.

Schein, E.H. (1995). 'Process consultation, action research and clinical inquiry: are they the same?', Journal of Managerial Psychology, 10, pp. 14-19.

Segrestin, B. (2005). 'Partnering to explore: The Renault-Nissan Alliance as a forerunner of new cooperative patterns', Research Policy, 34, pp. 657-672.

Shani, A.B., A. David and C. Wilson (2004). 'Collaborative research: Alternative roadmaps'. In N. Adler, A.B. Shani and A. Styhre (eds), Collaborative research in organizations, pp. 83-100. Thousand Oaks, CA: Sage.

Shani, A.B., and P. Docherty (2003). Learning by design: Building sustainable organizations. Oxford: Blackwell Publishing.

Shani, A.B., D. Chandler, J.-F. Coget and J.B. Lau (2009). Behavior in Organizations. An experiential approach, Ninth edition. McGraw-Hill Irwin.

Shani, A.B., S.A. Mohrman, W.A. Pasmore, B. Stymnse and N. Adler (2008). Handbook of Collaborative Management Research. Thousand Oaks, CA: Sage.

Shani, A.B., D. Coghlan and S. Cirella (2012). 'Action research and collaborative management research: More than meets the eye?', International Journal of Action Research, 8, pp. 45-67. 
Srivastava, P. (1987). 'Rigor and Practical Usefulness of Research in Strategic Management', Strategic 788 Management Journal, 8, pp. 77-92.

Stassart, P.M, V. Mathieu and F. Melard (2011). 'Reflexive audiovisual methodology: The emergence of “minority practices” among pluriactive stock farmers', Journal of Rural Studies, 27, pp. 403-413.

Stevaert, P. and J. Jiggins (2007). 'Governance of complex environmental situations through social learning: a synthesis of SLIM's lessons for research, policy and practice', Environmental Science and Policy, 10, pp. 575-586.

Steyaert, P., M. Barzman, J. Billaud, H. Brives, B. Hubert, G. Ollivier and B. Roche (2007), 'The role of knowledge and research in facilitating social learning among stakeholders in natural resources management in the French Atlantic coastal wetlands', Environmental Science and Policy, 10, pp. 537-550.

Symon, G., A. Buehring, P. Johnson and C. Cassell (2008). 'Positioning Qualitative Research as Resistance to the Institutionalization of the Academic Labour Process', Organization Studies, 29, pp. 1315-1336.

Thomas, K.W. and W.G. Tymon (1982). 'Necessary Properties of Relevant Research: lessons from recent criticisms of the organizational sciences', Academy of Management Review, 7, pp. 345-352.

Thomas-Hunt, M. C., T.Y. Ogden and M.A. Neale (2003). 'Who's really sharing? Effects of social and expert status on knowledge exchange within groups', Management Science 49, pp. 464-477.

Tsoukas, H. and R. Chia (2002). 'On Organizational Becoming: rethinking organizational change', Organization Science, 13, pp. 567-582.

Van Aken, J.E. (2005). 'Management Research as a Design Science: Articulating the Research Products of Mode 2 Knowledge Production in Management', British Journal of Management 16, pp. 19-36.

Van de Ven, A.H. and P.E. Johnson (2006). 'Knowledge for theory and practice', Academy of Management Review, 31, pp. 802-821.

Van Maanen, J. (1995). ‘Style as theory', Organization Science, 7, pp. 641-652.

Weick, K.E. (2001). 'Gapping the Relevance Bridge: fashions meet fundamentals in Management Research', British Journal of Management, 12, pp. 71-75.

Wertheimer, M. (1959). Productive thinking. New York: Harper.

Willmott, H. (1998). 'Re-cognizing the other: reflections of a new sensibility in social and organization studies'. In R. Chia (ed), In the Realm of Organization: Essays for Robert Cooper. London: Routledge. 


\begin{tabular}{|c|c|c|}
\hline & $\begin{array}{l}\text { The challenges identified in the } \\
\text { Management field }\end{array}$ & Responses by Intervention Research \\
\hline \multirow{3}{*}{$\begin{array}{l}\text { Theory } \\
\text { Advancement }\end{array}$} & $\begin{array}{l}\text { Place change and development at the center } \\
\text { of inquiry. }\end{array}$ & $\begin{array}{l}\text { Focus on an epistemology of action to identify, critique } \\
\text { and invent models of collective action }\end{array}$ \\
\hline & $\begin{array}{l}\text { Support multi-level analysis of } \\
\text { organizational phenomena. }\end{array}$ & $\begin{array}{l}\text { Focus on 'collective action', comprising the influence } \\
\text { of individuals, teams and the organization. }\end{array}$ \\
\hline & $\begin{array}{l}\text { Support polyphonic and non-relativistic } \\
\text { investigation of phenomena. }\end{array}$ & $\begin{array}{l}\text { Isonomic involvement of practitioners in the } \\
\text { investigation. }\end{array}$ \\
\hline \multirow[b]{2}{*}{ Rigor } & $\begin{array}{l}\text { Develop evaluation criteria for external } \\
\text { assessment }\end{array}$ & $\begin{array}{l}\text { - Accommodation } \\
\text { - Catalytic validity } \\
\text { - Authenticity through isonomic collaboration }\end{array}$ \\
\hline & $\begin{array}{l}\text { Facilitate access to organizational } \\
\text { phenomena }\end{array}$ & $\begin{array}{l}\text { - Contractual agreements that clearly state the research } \\
\text { purposes of the collaboration } \\
\text { - Investigation team composed of both researchers and } \\
\text { practitioners during the intervention process }\end{array}$ \\
\hline Relevance & Produce knowledge relevant to practitioners & $\begin{array}{l}\text { Design and implementation of management models, } \\
\text { tools and procedures that facilitate managerial change. }\end{array}$ \\
\hline
\end{tabular}


Table 2. Brief summary of the case

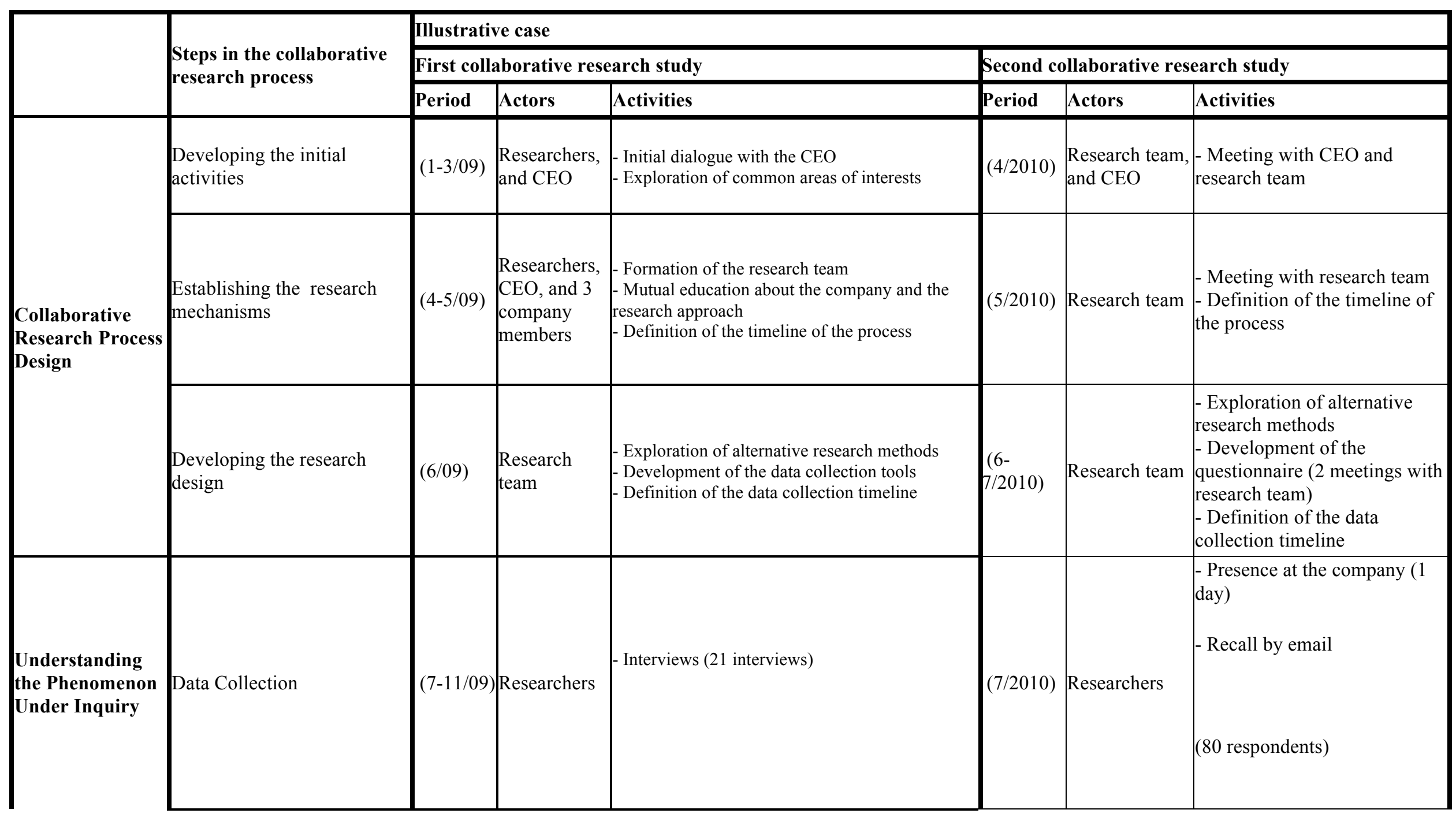




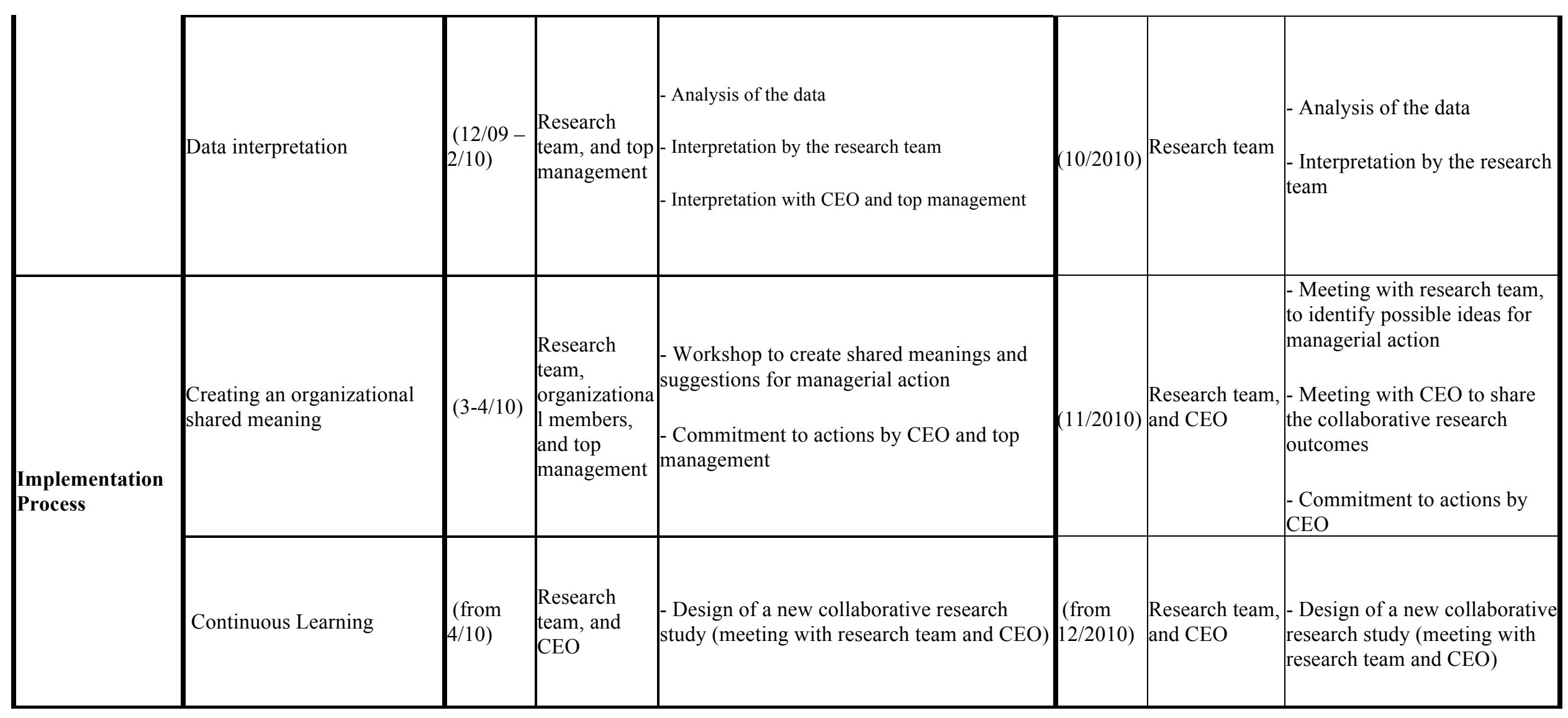


Table 3. Specific activities included in the IR protocol

\begin{tabular}{|l|l|}
\hline $\begin{array}{l}\text { Research macro-phases } \\
\text { (adapted from Avenier and Nourry, 1999) }\end{array}$ & Specific activities \\
\hline Collaborative research process design & $\begin{array}{l}\text { Mutual education and learning with top } \\
\text { management about the issues to be tackled by } \\
\text { the collaborative effort } \\
\text { Definition of the mechanisms, scope, resources, } \\
\text { and timeline of the research } \\
\text { Possible further mutual learning about the issues } \\
\text { and the possible scientific research methods to } \\
\text { be used } \\
\text { Design and management of ongoing } \\
\text { communication about the study with } \\
\text { organizational members }\end{array}$ \\
\hline Inquiry process & $\begin{array}{l}\text { Exploring alternative data collection methods } \\
\text { and processes and finalizing them } \\
\text { Training the research team/s in data collection } \\
\text { Systematic data collection } \\
\text { Initial data analysis by the research team } \\
\text { Developing the process for creating shared } \\
\text { meanings and data interpretations }\end{array}$ \\
\hline Implementation & $\begin{array}{l}\text { Identifying and formulating possible managerial } \\
\text { implications and actions, and possible further } \\
\text { research actions, based on the shared data } \\
\text { meaning/interpretation } \\
\text { Presenting the possible actions for change to top } \\
\text { management, top management decision about } \\
\text { ensuing actions and steps } \\
\text { Actual implementation of the actions }\end{array}$ \\
\hline
\end{tabular}


Table 4. Synopsis of the illustrative IR case

\begin{tabular}{|c|c|c|}
\hline & $\begin{array}{c}\text { The challenges identified in the } \\
\text { Management field }\end{array}$ & Illustrative IR Case \\
\hline \multirow{3}{*}{$\begin{array}{l}\text { Theory } \\
\text { Advancement }\end{array}$} & $\begin{array}{l}\text { Place change and development at the center } \\
\text { of inquiry. }\end{array}$ & $\begin{array}{l}\text { Production of two new models of collective action (i.e. } \\
\text { creativity as a collective phenomenon enabled and } \\
\text { accelerated by a tapestry of structural, procedural and } \\
\text { cognitive learning mechanisms) that inspired a planned } \\
\text { change process within the organization }\end{array}$ \\
\hline & $\begin{array}{l}\text { Support multi-level analysis of } \\
\text { organizational phenomena. }\end{array}$ & $\begin{array}{l}\text { Theoretical framework focusing on creativity at the } \\
\text { individual, team and organizational level } \\
\text { Model of action produced by the first study based on } \\
\text { the multi-level concept of collective creativity }\end{array}$ \\
\hline & $\begin{array}{l}\text { Support polyphonic and non-relativistic } \\
\text { investigation of phenomena. }\end{array}$ & $\begin{array}{l}\text { Involvement of different levels and different units of } \\
\text { the organization } \\
\text { Design of occasions intended to foster production of } \\
\text { shared meaning }\end{array}$ \\
\hline \multirow[t]{2}{*}{ Rigor } & $\begin{array}{l}\text { Develop evaluation criteria for external } \\
\text { assessment }\end{array}$ & $\begin{array}{l}\text { Accommodation: the models of action produced in the } \\
\text { case do not impose a course of action, but generate } \\
\text { guidelines that can be adapted by other companies } \\
\text { Catalytic validity: high response from organizational } \\
\text { members at different levels; planned set of managerial } \\
\text { actions based on findings; the fact that an IR research } \\
\text { project is still ongoing } \\
\text { Authenticity through isonomic collaboration: see OPP2 }\end{array}$ \\
\hline & $\begin{array}{l}\text { Facilitate access to organizational } \\
\text { phenomena }\end{array}$ & $\begin{array}{l}\text { Collaborative protocol whereby practitioners are } \\
\text { included in the research team } \\
\text { Contractual agreement that made explicit the objectives } \\
\text { of the research, signed by the senior researcher and the } \\
\text { CEO }\end{array}$ \\
\hline Relevance & Provide knowledge relevant to practitioners & $\begin{array}{l}\text { The models of collective action identified supported } \\
\text { the design and implementation of management models } \\
\text { (e.g. restructuring of the organization, reviews of } \\
\text { practices, redefinition of roles) }\end{array}$ \\
\hline
\end{tabular}

